Faculdade de Ciências Econômicas da UFRGS
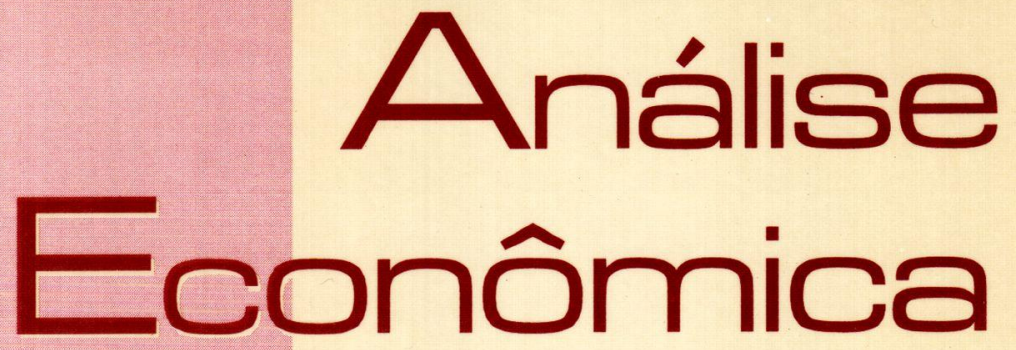

A Instabilidade Financeira dos Anos 90: Alqumas Implicações para as Economias Capitalistas Periféricas André Cunha e Daniela Prates

A Ampliação Recente da Participação Estrangeira no Sistema Bancário Brasileiro Maria Cristina Penido de Freitas

INFRA-ESTRUTURA dE INfORMAÇÕES E SISTEMA Nacional de InOvação

Eduardo da Motta e Albuquerque

Custo Social dos Recursos Hídricos em Bacias Hidrográlicas Internacionais: O Caso da Bacia do Paraná Jandir Ferrera de lima e José Carrera-Fernandez

Preferência pela liovidez e Escollha de Porrtólio

José Luis Oreiro

Eficiência, Objetivo e Coordenação da Política Macroeconômica no Período: 1974 - 1979

JoÃo Sicsú

Macroeconomia Moderna: Keynes e a ECONOMIA CONTEMPORÂNEA - Resenha

Simone Silva de Deos

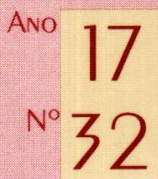


Universidade Federal do Rio Grande do Sul

Reitora: Proft. Wrana Maria Panizzi

Faculdade de Ciências Econômicas

Diretora: Prof ${ }^{a}$. Otilia Beatriz Kroeff Carrion

Centro de Estudos e Pesquisas Econômicas

Diretor: Prof. Fernando Ferrari Filho

Departamento de Ciencias Econômicas

Chefe: Prof Luiz Alberto Oliveira Ribeiro de Miranda

Curso de Pós-Graduação em Economia

Coordenador: Prof. Marcelo Savino Portugal

Curso de Pós-Graduaçāo em Economia Rural

Coordenador: Prof. Carlos Guilherme A. Mielitz Netto

Conselho edtrorial

Achyles B. Costa, Aray M. Feldens, Carlos A. Crusius, Carlos G. A. Mielitz Netto, Eduardo A. Maldonado Filho, Eduardo P. Ribeiro, Eugênio Lagemann, Fernando Ferrari Filho, Gentil Corazza, Marcelo S. Portugal, Nali J. Souza, Otilia B. K. Carrion, Paulo A. Spohr, Paulo D. Waquil, Pedro C. D. Fonseca, Roberto C. Moraes, Ronald Otto Hillbrecht, Stefano Florissi, Eleutério F. S. Prado (USP), Fernando H. Barbosa (FGV/RJ), Gustavo Franco (PUC/RJ), João R Sanson (UFSC), Joaquim P. Andrade (UnB), Juan H. Moldau (USP), Paul Davidson (Univ. of Tennessee), Werner Baer (Univ. of Illinois).

Comissão EDITORLAL

Eduardo Augusto Maldonado Filho, Fernando Ferrari Filho, Gentil Corazza, Marcelo Savino Portugal, Paulo Dabdab Waquil; Roberto Camps Moraes.

EDrTor: Gentil Corazza

Edrror Adjunto: Pedro Silveira Bandeira

SeCretaria: Laize Espindula.

REVISÃo DE TEXTos: Vanete Ricacheski.

Fundador: Prof. Antônio Carlos Santos Rosa

Os materiais publicados na revista Análise Econômica são da exclusiva responsabilidade dos autores. É permitida a reprodução total ou parcial dos trabalhos, desde que seja citada a fonte. Aceita-se permuta com revistas congêneres. Aceitam-se, também, livros para divulgação, elaboração de resenhas e recensões. Toda correspondência, material para publicação (vide normas na terceira capa), assinaturas e permutas devem ser dirigidos ao seguinte destinatário:

Prof, Gentul Corazza

Revista Análise Econômica - Av. João Pessoa, 52 CEP 90040-000 PORTO ALEGRE - RS, BRASIL

Telefones: 0xx (51) 316-3348 e 316-3440 - Fax: 0xx (51) 316-3990 rae@vortex.ufrgs.br

Análise Econômica

Ano 17, n. 32, setembro, 1999 - Porto Alegre

Faculdade de Ciências Econômicas, UFRGS, 1999

Periodicidade semestral, março e setembro.

ISSN 0102-9924

1. Teoria Econômica - Desenvolvimento Regional -

Economia Agrícola - Pesquisa Teórica e Aplicada -

Periódicos. I. Brasil.

Faculdade de Ciências Econômicas,

Universidade Federal do Rio Grande do Sul.

CDD 330.05

CDU 33 (81) (05) 


\title{
O custo social dos recursos hídricos em bacias hidrográficas internacionais: $O$ caso da bacia do Paraná.
}

\author{
José Carrera-Fernandez*
}

Jandir Ferrera de Lima* *

\begin{abstract}
Sinopse: Este artigo levanta algumas questões sobre o uso adequado dos recursos hídricos superficiais em bacias hidrográficas internacionais e trata especificamente do caso da Bacia do Rio Paraná, a qual integra a Bacia do Prata, onde estão situados os principais países do Mercosul. Ao longo das margens do Rio Paraná estão localizados inúmeros centros urbanos, plantas industriais e empreendimentos agrícolas de irrigação que, além de captarem água desse manancial, se utilizam dele como corpo receptor para diluírem seus efluentes, contaminando, assim, suas águas com os mais variados poluentes e índices de concentração, os quais acabam sendo exportados para os países a jusante, principalmente para a Argentina e o Uruguai, principais parceiros do Brasil no Mercosul. Este trabalho analisa os desafios do Mercosul sob o ponto de vista do uso eficiente dos recursos hídricos e do meio ambiente, associados com o comércio entre os países membros, principalmente o Brasil, como grande usuário dos recursos hídricos, e chama a atenção para o fato que a utilização da água pelos múltiplos usuários na economia brasileira impõe custos sociais aos outros países, devido ao aumento nos custos de despoluição e uma menor disponibilidade hídrica, os quais não são levados em consideração no comércio entre esses países.
\end{abstract}

Palavras-chave: Mercosul; Meio Ambiente; Recursos Hídricos; Custo Social.

\begin{abstract}
This paper raises some questions about the suitable use of superficial water resources in international hydrographical basins, and examines specifically the Paraná basin case, which integrates the Prata basin, where are located the main countries of Mercosul trade area. On the Paraná river shore are located many urban centers, industrial plants, and agricultural undertakings of irrigation which, besides to abstracting water from this source, use this river as a receiver body to dilute their rejects, polluting its waters with a variety of pollutants and levels of concentration, which are exported to downstream countries, mainly Argentina and Uruguai, which are Brazilian main partners in the Mercosul trade area. This work analyzes the challenges of the Mercosul under the viewpoint of efficient use of water resources and environment, associated with trade among these countries, mainly the Brazil, as a larger user of water resources, and calls attention to the fact that Brazilian multiple utilization of water resources imposes social costs on these countries, due to increase of depollution costs and lower water availability, which are not accounted through trade among these countries.
\end{abstract}

Key words: Mercosul; Water Resources; Environment; Social Costs.

\footnotetext{
* Professor do Mestrado em Economia da Universidade Federal da Bahia e PhD* em Economia pela The University of Chicago

"Professor do Departamento de Economia da Universidade Estadual do Oeste do Paraná (UNIOESTE) e Mestre em Ciências Econômicas pela Universidade Federal da Bahia(UFBa).
} 


\section{Introdução}

Dentro da caracterização de uma bacia hidrográfica, os recursos hídricos desempenham um papel preponderante. Sob o ponto de vista do planejamento regional as bacias hidrográficas passam a assumir um papel estratégico, tanto em nível de sistemas, quanto em nível de mudanças econômicas. Conseqüentemente, analisá-la dentro de um ambiente físico, social e econômico é essencial, mas a lógica desta importância muda de tempos em tempos, o que implica estar atentos a possíveis transformações e alterações econômicas gerais.

Frente às mudanças estruturadas pelo mercado, os projetos de sustentação econômica que venham a se formar necessitam adequar-se ao dinamismo do meio físico e social, e a viabilidade desses projetos deve estar vinculada às condições de vida salutares num futuro onde se desenha uma revolução tecnológica extremamente complexa. Por isso mesmo, o processo de crescimento da região platense (ou Platina) deve ser integrativo, e o desenvolvimento deve ser distribuído e polarizado dinamicamente nas suas sub-regiões, levando-se em consideração o aproveitamento ótimo e racional dos recursos naturais entre os seus vários usuários, viabilizando, assim, o seu uso pelas gerações futuras.

A escolha da Bacia do Prata para esse estudo advém de uma compreensão do novo papel geoeconômico e geopolítico que os países integrantes dessa Bacia delineiam, ao estarem interligados estrategicamente por recursos internacionais, tendo pela frente os acordos comerciais que advêm do Mercosul. Os impactos desta transformação econômica e política mudam profundamente o perfil da estrutura regional, dentro dos eixos agrícolas e urbanos, onde os recursos hídricos para a produção e consumo, tornam-se cada vez mais um fator escasso e preponderante para boas condições de vida dessa comunidade emergente.

Outrossim, os elementos de espaço e potencialidades são fatores de viabilidade econômica e de estabilidade social. A referência disto é que, se no curto prazo não forem implementadas formas mais racionais de utilização dos recursos hídricos, já no início do século XXI, aproximadamente $90 \%$ dos lençóis freáticos estarão contaminados por agrotóxicos e resíduos industriais e urbanos. Em vista disso é que este trabalho se debruça sobre a questão do custo social dos recursos hídricos em bacias hidrográficas internacionais, tendo a bacia do Rio Paraná como estudo piloto, ademais da característica nodal desta região sobre a Bacia do Prata, ou seja, uma região polarizada com interdependência entre as várias áreas. Essa interdependência é caracterizada pela sua interconexão através de fluxos de relações econômicas, políticas e culturais, onde “... os fluxos variam diretamente com o tamanho (ou atração) do nódulo e inversamente com a distância." (RICHARDSON, 1973, p. 204). 
Esta interdependência pode ser identificada pela proximidade do Nordeste Argentino com o Oeste Brasileiro (Estado do Paraná), entre as fronteiras paraguaias, bolivianas e brasileiras, o que contrasta uma influência latente nas políticas de desenvolvimento desses países. No momento em que a hidrovia do Paraná serve de eixo de integração e irradiação de crescimento a várias regiões, e nas suas margens está todo um complexo agropecuário e industrial, seu estudo torna-se essencial para analisar o uso adequado dos recursos hídricos de escorrimento superficial para o crescimento econômico, e na estruturação política que o espaço econômico incorpora quando os recursos estão distribuídos entre diferentes países.

Ao longo das margens do Rio Paraná estão localizados inúmeros centros urbanos, plantas industriais e atividades agrícolas de irrigação que, além de captarem água desse manancial, se utilizam dele como corpo receptor para diluírem seus efluentes, contaminando suas águas com os mais variados poluentes e índices de concentração, os quais acabam sendo exportados para os países a jusante, principalmente para a Argentina e o Uruguai, principais parceiros do Brasil no Mercosul.

A questão do gerenciamento integrado dos recursos hídricos entre os países platenses tem atraído a atenção de seus governos e tem merecido certo destaque na política econômica desses países, principalmente com o advento do Mercosul. Nesse sentido, o uso adequado e mais eficiente das águas desse manancial é essencial tanto para atender as populações que dele se servem e retiram o próprio sustento, quanto dar continuidade às atividades econômicas desenvolvidas nessas regiões e fortalecer o próprio comércio entre esses países. Este artigo levanta algumas questões sobre o uso adequado dos recursos hídricos superficiais em bacias hidrográficas internacionais e trata especificamente o caso da bacia do Rio Paraná.

A utilização dos recursos hídricos por qualquer usuário em um sistema de bacia hidrográfica gera, via de regra, efeitos externos (externalidades tecnológicas) sobre os demais usuários do sistema, os quais não são contabilizados pelo mercado através do mecanismo de preços. Estes efeitos externos são o resultado da falta ou indefinição dos direitos de propriedade ou, pelo menos direitos de uso, dos recursos hídricos, o que impossibilita estabelecer relações de troca que garantam uma utilização eficiente desses recursos. Nestes casos, o valor econômico dos recursos hídricos realizado no mercado subestima o seu custo social, gerando assim uma alocação ineficiente desses recursos no sistema.

Como agravante, os recursos hídricos nesses países estão sendo considerados, via de regra, como bens livres oferecidos pela natureza e, portanto, cotados ao preço zero, guardando apenas associação com os custos 
privados decorrentes da sua utilização. Pior do que isso, é que os rejeitos da produção de qualquer agente econômico sempre foram descartados em corpos d'água sem a menor "cerimônia", sem nenhuma implicação de custos para o agente poluidor. Conscientizar o usuário a utilizar os recursos de água mais racionalmente vem sendo uma restrição estritamente social, entendida como norma de comportamento e boas maneiras. $O$ fato é que o sistema econômico, por si só, não é suficientemente capaz de otimizar o uso dos recursos hídricos. Ademais, regulamentos, normas e regras emanadas do poder público têm-se mostrado tradicionalmente ineficazes para atingir seus objetivos. Além disso, os recursos hídricos começam a dar, aqui e ali, sinais de exaustão, tanto em quantidade quanto em qualidade, muitas vezes gerando conflitos entre usuários competidores, com elevados custos sociais, cada vez mais difíceis de serem administrados.

Diante da iminência de exaustão dos recursos hídricos, tanto nas suas dimensões quantitativas quanto qualitativas, é preciso então traduzir essas restrições sociais normativas em restriçôes de natureza econômica, avaliando-se conjuntamente disponibilidades e demandas por água, nas várias modalidades de usos múltiplos, quer sejam eles consuntivos ou não-consuntivos, bem como estabelecer mais rapidamente um sistema de compensação financeira entre os países platenses para que os usuários dos recursos hídricos internalizem aos custos privados os custos sociais impostos a toda a comunidade do Mercosul.

Introduzir custos ambientais nas atividade de produção e consumo pode vir a ser um mecanismo importante de incrementar a eficiência do sistema, na medida em que internaliza aos custos privados os custos sociais dos recursos, sinalizando para os agentes econômicos preços que representam o verdadeiro custo de oportunidade para a sociedade. Os custos resultantes da redução da produção, por conta deste processo de internalização, são mais do que compensados pelos ganhos em bem-estar advindos da melhoria ambiental, de modo que a internalização dos custos ambientais aos custos privados sempre confere aos seus agentes ganhos sociais líquidos.

\section{Caracterização da Bacia do Prata}

A Bacia do Prata é formada pelos rios Paraguai, Paraná e Uruguai e seus afluentes, os quais têm suas nascentes em território brasileiro, estende-se por uma superfície de 3,1 milhões de $\mathrm{Km}^{2}$ e abrange o território de cinco países da América do Sul: Brasil, Paraguai, Uruguai, Argentina e Bolívia. O rio Paraná, com uma extensão de $4 \mathrm{mil} \mathrm{km²}$, é o recurso hídrico mais importante da Bacia do Prata, tanto sob o ponto de vista geográfico quanto político, estendendo-se pelos territórios do Brasil, Paraguai e Argentina. O QUADRO 1 contém os 
principais aspectos físicos e demográficos, bem como as relações geográficas na Bacia do Prata.

Quadro 1: Aspectos físicos, demográficos e relações geográficas na Bacia do Prata

\begin{tabular}{|l|l|l|c|c|c|}
\hline País & $\begin{array}{l}\text { Superfície } \\
\text { total }\left(\mathrm{km}^{2}\right)\end{array}$ & $\begin{array}{l}\text { População em } \\
2.000 \\
\text { (mil hab. })\end{array}$ & $\begin{array}{l}\text { Superfície da } \\
\text { bacia }\left(1.000 \mathrm{~km}^{2}\right)\end{array}$ & $\begin{array}{l}\text { \% da bacia } \\
\text { no país }\end{array}$ & $\begin{array}{l}\text { \% do país } \\
\text { na bacia }\end{array}$ \\
\hline Argentina & 2.766 .656 & 32.860 & 920 & 32 & 37 \\
\hline Bolívia & 1.098 .581 & 10.267 & 205 & 6 & 19 \\
\hline Brasil & 8.511 .965 & 212.508 & 1.415 & 44 & 17 \\
\hline Paraguai & 406.752 & 5.592 & 410 & 13 & 100 \\
\hline Uruguai & 186.926 & 3.993 & 150 & 5 & 80 \\
\hline
\end{tabular}

Fonte: Instituto Interamericano de Estatística e Ministério da Integração Regional do Brasil.

As áreas drenadas pelos rios Paraná, Paraguai e Uruguai são lançadas no estuário do Rio da Prata, entre os territórios da Argentinas e do Uruguai, delineando aquela que é a quarta maior bacia hidrográfica do mundo, abrangendo $30 \%$ da área total da América do Sul e junto com as bacias hidrográficas dos rios Amazonas e Orinoco (Venezuela) constituem 45\% da superfície da América Latina, $70 \%$ das águas superficiais e abrangem $10 \%$ da população (CEPAL, 1980). O fato mais relevante talvez seja o de que cinco países estão situados no seu âmbito, ressaltando a importância política e econômica do ambiente envolvido, que "...considerando sua imensa riqueza natural, a região pode ser considerada, junto com a Amazônia, a Sibéria e o Oriente Próximo uma das mais ricas do mundo." (SCHILLING, 1981, p.122).

Estas condições propicias a geração de riquezas, no tocante a produção agropecuária, advêm da riqueza hídrica e das condições climáticas. De acordo com informações da CEPAL (1990), 40\% da região platense está situada em área tropical e o restante em subtropical. $\mathrm{Na}$ área tropical, onde a temperatura média máxima no inverno é de $13^{\circ} \mathrm{C}$, está localizado o sudeste do Paraguai e a Região do Chaco, o extremo noroeste argentino, o sudeste da Bolívia, e no Brasil constitui uma parcela do Mato Grosso, São Paulo, Minas Gerais, Brasília e a Região Sul. $\mathrm{Na}$ área subtropical, onde a temperatura média máxima no inverno oscila entre 6 e $13^{\circ} \mathrm{C}$, localiza-se a maior parte da região Argentina da Bacia, com exceção da zona tropical, o oeste e o oriente do Rio Grande do Sul, bem como as serras de Santa Catarina e Paraná, no Brasil, e a totalidade do Uruguai. As precipitações pluviométricas se situam na faixa de 600 a 1800 mm anuais, variando de acordo com as regiões.

A navegação é um dos usos mais importantes desta bacia. Dos mais de 6 mil km navegáveis na Bacia do Prata, $4.625 \mathrm{Km}$ são atualmente navegados. Só no rio Paraná são $2.400 \mathrm{Km}$, com capacidade de carga de 4.400 t. Com o transbordo da carga em Itaipu, o único obstáculo com um desní- 
vel de $115 \mathrm{~m}$, a extensão da hidrovia é de $4.500 \mathrm{Km}$ navegáveis e representa a interligação de toda região do Mercosul, tornando-se estratégica para o fortalecimento do comércio entre esses países. Além disto, alguns estudos técnicos prevêem a interligação desta bacia com as bacias Amazônica e a do Nordeste, através de algumas obras de infra-estrutura, tais como canais e eclusas, entre outras.

A região da Bacia do Prata conta com várias fontes de energia que poderão vir a ser exploradas com impactos ambientais relativamente reduzidos. Os três rios que compõem a Bacia do Prata geram um aproveitamento hidroelétrico brasileiro de cerca de $230 \mathrm{MW}$, o que representa quase $80 \%$ de toda a produção de energia elétrica desses países nessa região. Além da energia hidroelétrica, existem na região o petróleo, o carvão e o gás natural como fontes energéticas alternativas.

A exploração dessas riquezas viabiliza os assentamentos humanos, dão-se condições de sobrevivência às populações e estimula-se o processo de acumulação de capital, através do favorecimento à instalação de indústrias, escoamento da produção e acesso aos insumos básicos. Uma parcela dessa riqueza pode ser vislumbrada pela produção das principais fontes energéticas, expostas no Quadro 2.

Quadro 2: Capacidade de produção das principais plantas energéticas na Bacia do Prata (1990)

\begin{tabular}{|l|c|c|c|}
\hline \multirow{2}{*}{ País } & \multicolumn{3}{|c|}{ Planta } \\
\cline { 2 - 4 } & $\begin{array}{c}\text { Hidroelétrica } \\
(\mathrm{MW})\end{array}$ & $\begin{array}{c}\text { Termoelétrica } \\
(\mathrm{MW})\end{array}$ & $\begin{array}{c}\text { Ref. Petróleo (barris } \\
\text { diários) }\end{array}$ \\
\hline Argentina & 938,6 & 6.065 & 489.080 \\
\hline Bolívia & 2,0 & - & 3.050 \\
\hline Brasil * & $39.439,9$ & 1.277 & 445.600 \\
\hline Paraguai & 180,0 & - & 5.000 \\
\hline Uruguai & 252,0 & 280 & 43.000 \\
\hline Uruguai/Argentina & $1.890,0$ & - & - \\
\hline Total & $42.702,5$ & 7.622 & 985.730 \\
\hline
\end{tabular}

Fonte: CEPAL, 1990.(*) Dados de 1997, conforme informação do DNAEE (Depto. Nacional de Águas e Energia Elétrica.

Em nível industrial, o QUADRO 3 apresenta as principais atividades e as suas respectivas produçóes por país na Bacia do Prata. A partir dessas potencialidades, observa-se que a exploração econômica da bacia do Prata tem uma relação direta com a utilização dos corpos d'água superficiais, cujo aproveitamento dos recursos hídricos para atender ao consumo industrial foi estimado na ordem de $240 \mathrm{~m}^{3} / \mathrm{s}$ (CEPAL, 1990). Com isso, a gestão dos recursos hídricos passa a ser preponderante, principalmente quando as indústrias aí situadas são altamente poluentes. Destas, a indústria de papel e celulose são as que mais contaminam os corpos d'água. De acordo com a CEPAL (1990a), há 
uma produção de efluentes por estas empresas na ordem de $200 \mathrm{~m}^{3}$ por tonelada de celulose, e $110 \mathrm{~m}^{3}$ por tonelada de papel. Geralmente a água é utilizada para a lavagem da madeira e seu amolecimento, bem como o processo de branqueamento e revestimento do papel, em que misturam-se outros produtos químicos. Após este processo, estima-se que sejam despejados em torno de $27 \mathrm{~m}^{3} /$ $s$ de resíduos nos rios. Já a refinação de petróleo produz em torno de 380 litros de efluentes por barril de óleo cru. Estima-se que o despejo de resíduos chega à ordem de $24 \mathrm{~m}^{3} / \mathrm{s}$, enquanto a siderurgia produz em média $25 \mathrm{~m}^{3}$ de efluentes por tonelada produzida. Nesta faixa também se encontram os efluentes lançados nos corpos d'água. Fora este fato, a siderurgia produz em média 1.762.700 toneladas de sólidos em suspensão, além de outros produtos químicos. Por outro lado, as refinarias de metais ferrosos geram em torno de $20 \mathrm{~m}^{3} / \mathrm{s}$ de efluentes por tonelada produzida. A fundição e o refinamento de cobre representa a maior parte do potencial poluidor (CEPAL, 1990a).

Quadro 3: Produção das principais atividades industriais na Bacia do Prata, 1990 (toneladas/ano)

\begin{tabular}{|l|l|l|l|l|l|}
\hline \multirow{2}{*}{ Atividade } & \multicolumn{5}{|c|}{ País } \\
\cline { 2 - 6 } & Argentina & Brasil & Paraguai & Uruguai & Total \\
\hline Siderurgia & 3.619 .000 & 1.271 .000 & - & - & 4.890 .000 \\
\hline Celulose & 271.500 & 386.200 & - & 13.600 & 671.300 \\
\hline Papel & 755.500 & 613.420 & 1.200 & 55.600 & 1.425 .720 \\
\hline $\begin{array}{l}\text { Metais não- } \\
\text { fer. }\end{array}$ & 43.000 & 229.200 & & - & 272.200 \\
\hline
\end{tabular}

Fonte: CEPAL, 1990.

Deve-se ressaltar que existe na Bacia do Prata uma relação de dependência de alguns países, principalmente o Paraguai e a Bolívia, quanto ao uso adequado dos recursos naturais renováveis e ao potencial de integração que os mesmos representam, já que são países mediterrâneos, colocandoos na influência direta das duas maiores economias do Cone Sul, que são a brasileira e a argentina. A Argentina e o Uruguai, por outro lado, dependem mais diretamente do uso adequado dos recursos hídricos, já que se encontram na desembocadura da bacia, no estuário do Prata.

Em vista do exposto, nota-se que a importância econômica advêm das várias áreas de produção agrícola, mineral e industrial. Fator de maior significado dentro das relações comerciais do Mercosul, o que demonstra um ambiente de proximidade de mercados, escoamento de produção e perfeito espaço para a criação de novos pólos industriais, fato mais preeminente com a estrutura hidroviária. Já a sua importância política surge com a característica de fronteira permanente, haja vista que na Bacia situam-se cinco nações, compartilhando a utilização dos principais recursos hídricos, o que envolve um jogo estratégico no momento em que a estrutura de um país abrange espaço geográ- 
fico plenamente integrado ou sob sua órbita, e a Bacia do Prata constitui-se "um dos mais importantes e ricos 'espaços vazios' do mundo, seu futuro interessa a toda América Latina e pode significar - sempre que seja racionalmente explorada - muito para o futuro da própria humanidade." (SCHILLING, 1981, p.122).

Com isto, nota-se que o aproveitamento da Bacia está diretamente relacionado ao aproveitamento dos recursos hídricos que a compõem, tanto quanto à sua extração, utilização e aproveitamento. Esta relação pode ser caracterizada pelos próprios países que dela fazem uso, norteando todo o seu aproveitamento econômico e político, visto que "com a exploração racional de suas imensas riquezas, o território da mesopotânia sul-americana poderia proporcionar condições excepcionais de vida para $300 / 400$ milhões de habitantes." (SCHILLING, 1981, p.122). No contexto histórico da Bacia, as vias de acesso à conquista interna do continente sul-americano deram-se através da penetração pelos rios. $\mathrm{Na}$ atualidade, a indústria e a geração de energia elétrica, a água em reservatórios e a drenagem para atender à agricultura irrigada, o suporte ao consumo de água potável, bem como a navegação constituem o ponto de exploração dos recursos hídricos que dão sustentação às atividades econômicas e a qualidade de vida dessas populações. Nenhuma diligência econômica se realiza sem um aproveitamento do espaço das regiões, o que é delineado pelo ambiente geográfico e político.

A importância histórica da Bacia do Prata vê-se hoje ressaltada com a integração comercial desses países, visto que estes recursos hídricos são fundamentais para o desenvolvimento da região dentro do novo contexto do sistema produtivo internacional de tecnologias limpas e de preservação ambiental.

\section{A gestão conjunta dos recursos hídricos na Bacia do Prata}

Embora a gestão conjunta dos recursos hídricos na bacia hidrográfica do Prata já estivesse prevista desde o final da década de 60, a efetiva preocupação só mereceu destaque com o advento do Mercosul. O primeiro acordo firmado entre os países platenses, denominado de Tratado da Bacia do Prata, já data de 23 de abril de 1969. Este tratado estabelece as bases para uma política fluvial conjunta, na medida em que lança tópicos de estudo para um melhor aproveitamento, manutenção e preservação dos recursos hídricos utilizados pelos países signatários. Conforme LIMA (1997), dentre eles, destacam-se: (a) formas de controle de enchentes, erosões e assoreamento dos principais rios da Bacia do Prata, dentre eles o Rio Uruguai, o Rio Paraguai e o Rio Paraná; (b) controle e pesquisa da flora e da fauna para preservação do meio ambiente; (c) usos 
múltiplos da água, principalmente para a agricultura irrigada e para a indústria, tanto no abastecimento quanto como para diluição de efluentes líquidos; (d) levantamento do potencial hidroelétrico; e (e) busca de assistência à hidronavegação, visando à integração da Bacia.

Vale a pena ressaltar que este tratado veio de encontro, principalmente, aos interesses argentinos e paraguaios, já que "as águas da bacia do Prata são a única fonte de abastecimento para bebida e para as indústrias das grandes cidades do litoral argentino, inclusive a grande Buenos Aires e Rosário (Doze milhões de habitantes)" (SCHILLING, 1981, p.123).

Com referência aos problemas dos recursos hídricos da Bacia do Prata, salienta-se que:

Além da maior dependência e de ter menor possibilidade de utilizar os recursos naturais da região, a Argentina (juntamente com o Uruguai) é a que maior riscos vai correr com o aproveitamento das águas dos rios da Bacia... Seriam igualmente a Argentina e o Uruguai os grandes prejudicados pela contaminação das águas dos rios, pela instalação indiscriminada de indústrias "sujas" no Brasil, na região beneficiada pelas hidrelétricas. O estuário do Prata poderia ser transformado numa enorme cloaca. (SCHILLING, 1981, 124).

Em vista do exposto, a Argentina buscou a mudança de uma cláusula firmada na declaração de Assunção (Tratado da Bacia do Prata), ratificada em 3 de junho de 1971, a qual estipulava que, em rios de curso sucessivo, cada Estado signatário da Bacia do Prata poderia aproveitar os seus recursos hídricos dentro de seu território de acordo com suas necessidades, procurando não causar danos aos Estados vizinhos.

Alegando que esta cláusula a prejudicava, a Argentina solicitou uma revisão do Tratado. Na Assembléia Geral das nações Unidas, em 1972, chegouse a um acordo em que as nações da Bacia do Prata “... na exploração, aproveitamento e desenvolvimento de recursos naturais os Estados não devem causar efeitos prejudiciais em zonas situadas fora de sua jurisdição." (SCHILLING, 1981, p.129), ficando os países comprometidos a informar os dados técnicos referentes aos usos empreendidos pelas nações signatárias, dentro de suas fronteiras, não impedindo os referidos Estados de continuar os projetos e os trabalhos de utilização do potencial da bacia em andamento.

Em relação ao Paraguai, já há naquele país a Comissão Nacional de Hidrovia Paraguai-Paraná, encarregada de coordenar a participação do Paraguai na navegação fluvial dos rios Paraguai-Paraná. Ademais,.o "Paraguai é o segundo país melhor colocado com relação ao aproveitamento das águas do 
Paraná. Nos projetos ótimos de utilização do potencial do rio, o país guarani seria, necessariamente, o sócio do Brasil e da Argentina." (SCHILLING, 1981, p. 124).

O Brasil possui uma posição estratégica em relação aos recursos hídricos na Bacia do Prata. "O principal rio, o Paraná, nasce em seu território trazendo o maior caudal de águas [...], o Brasil tem em suas mãos a válvula de admissão das águas [...] Uma utilização incontrolada das águas, ou a contaminação/poluição das mesmas, [...] poderia comprometer irremediavelmente o desenvolvimento dos países vizinhos." (SCHILLING, 1981, p.124).

Este problema se coloca mais sério, quando a região centro-sul passa por uma nova fase de investimentos em novas plantas industriais como, por exemplo, a expansão dos pólos petroquímicos do sul do Brasil, a instalação de novas montadoras de automóveis, a expansão das plantas industriais de celulose e papel, às margens do Rio Paraná.

Deve-se ressaltar que as nascentes dos principais rios platenses localizam-se em território brasileiro, o que coloca o Brasil em posição privilegiada diante dos seus vizinhos. Já a Argentina e o Uruguai estão em uma posição de maior dependência, já que estes países se encontram na desembocadura dos principais rios, tendo inclusive suas capitais, Buenos Aires e Montevidéu, respectivamente, inseridas nas áreas de maior influência. $O$ consumo desordenado e indiscriminado dos recursos hídricos e a poluição de seus mananciais por efluentes industriais e urbanos no território brasileiro acarretam conflitos entre usuários múltiplos tanto no próprio país como nos países a jusante, os quais podem futuramente agravar-se ainda mais, com prejuízos para a toda a sociedade do Mercosul ( LIMA, 1997).

Neste sentido, o consumo excessivo e a poluição dos recursos hídricos por parte dos brasileiros, principalmente em períodos de estiagem, configuram-se como externalidades tecnológicas impostas aos usuários a jusante, não contabilizadas pelo mecanismo de mercado através do sistema de preços, gerando uma alocação ineficiente desses recursos nessas economias, ademais de impor custos sociais a esses países, os quais são forçados a despender mais recursos financeiros para despoluição desses mananciais.

O gerenciamento integrado dos recursos hídricos nesta Bacia justificase pela necessidade de cuidados com a saúde humana, principalmente quando as águas são utilizadas para diluição de efluentes industriais e urbanos. Só para se ter uma idéia, na área de abrangência da Bacia do Prata, as descargas brasileiras de águas residuais domésticas chegam a 11,56 m³ $/ \mathrm{s}^{1}$ (CEPAL, 1990a). Este fato contrasta com a crescente demanda d'água para abastecimento humano nas regiões mais densamente povoadas, onde geralmente se

\footnotetext{
${ }^{1}$ As descargas de efluentes domésticos na área de abrangência da Bacia são da ordem de $9,70 \mathrm{~m}^{3} / \mathrm{s}$ na Argentina, $0,43 \mathrm{~m}^{3} / \mathrm{s}$ no Uruguai e $0,32 \mathrm{~m}^{3} / \mathrm{s}$ no Paraguai.
} 
concentram as atividades econômicas de transformação, as quais também exercem demanda sobre os recursos hídricos para o próprio abastecimento, bem como para diluição de seus efluentes.

Se as questões ambientais, principalmente aquelas relacionadas com os recursos hídricos, não forem tratadas prioritariamente pelos grupos de trabalho que se encarregam dessa matéria, os desequilíbrios ambientais entre os países membros do Mercosul podem se acentuar ainda mais com a intensificação do comércio entre esses países.

\section{O referencial metodológico}

Em um mundo "ideal", no qual os mercados operam livremente, em condições de concorrência perfeita, com pleno emprego e perfeita mobilidade dos recursos, o preço de mercado seria um bom indicador do valor dos bens para a sociedade. Entretanto essas condições ideais são raramente verificadas em prática, de modo que o sistema de preços de mercado passa a não ser um bom indicador dos custos para a sociedade, uma vez que estes preços contêm uma série de distorções, em relação às condições ideais de equilíbrio.

Nessas circunstâncias, as decisões de investimento, quando baseadas nos preços praticados pelo mercado, levam a economia a alocar os seus recursos de forma ineficiente. Portanto é necessário introduzir mecanismos que corrijam as divergências entre os preços de mercado e os preços sociais, orientando as ações de investimento, de modo a reduzir o uso dos recursos subavaliados ou ampliar a utilização dos recursos superavaliados pelo mercado, o que só é conseguido através da adoção de uma política explicita baseada nos preços sociais desses recursos.

Produzir com tecnologias mais limpas e, portanto, incorrer em menores riscos ambientais é um sinal de eficiência no contexto da globalização e inserção da economia brasileira no mercado internacional, visto que a poluição dos recursos hídricos é um insumo de produção não contido no produto final, mas que afeta negativamente a produção e os padrões ambientais de seus parceiros do Mercosul. Sanções comerciais de cunho ambiental podem, em um futuro próximo, vir a ser problemas reais para a economia brasileira, na medida em que podem restringir suas exportações não apenas para os países do Mercosul, mas também para os outros países, principalmente aqueles mais preocupados com a questão ambiental.

O problema ambiental pode ser formulado comparando-se os níveis ótimos de utilização da água na economia brasileira com aqueles níveis utilizados pelos outros países a jusante, afetados que são pela má utilização dos recursos hídricos. A utilização ótima de água na economia brasi- 
leira, $\mathrm{x}_{\mathrm{b}}{ }^{*}$, é obtida através da maximização da sua função de excedente econômico, $\mathrm{p}_{\mathrm{b}}$ :

$$
\max \pi_{b}=p_{b} f\left(x_{b}\right)-w_{b} x_{b}, \text { com } f^{\prime}=\partial t / \partial x_{b}>0
$$

Onde $p_{b}$ é o índice geral de preços da economia brasileira; $x_{b}$ é a quantidade dos recursos hídricos utilizada na economia brasileira; $\mathrm{e} \mathrm{w}_{\mathrm{b}}$ o preço desses recursos no Brasil, em termos de seus custos marginais de utilização da água; e $\mathrm{f}\left(\mathrm{x}_{\mathrm{b}}\right)$ é a função de produção brasileira agregada. O nível ótimo de utilização da água no economia brasileira é obtido através da condição necessária para um máximo interior ${ }^{2} \mathrm{p}_{\mathrm{b}} \mathrm{f}^{\prime}\left(\mathrm{x}_{\mathrm{b}}\right)=\mathrm{w}_{\mathrm{b}}$, estabelecido pela igualdade entre o valor da produtividade marginal da água e o preço desse recurso no Brasil.

Por outro lado, o nível ótimo de utilização da água nos outros países a jusante é derivado a partir da maximização da função de excedente econômico nesses países, $\pi_{0}$ :

$$
\max \pi_{o}=p_{o} g\left\{x_{o}, h\left[f\left(x_{b}\right)\right]\right\}-\underset{x_{o}}{w_{o} x_{o}, \operatorname{com} g}=\partial g / \partial x_{o}>0 \text { e } g_{h}=\partial g / \partial h<0
$$

Onde $\mathrm{p}_{\mathrm{o}}$ é o índice geral de preços nesses países; $\mathrm{x}_{\mathrm{o}}$ é a quantidade agregada de recursos da água utilizada nas economias desses países; $w_{\mathrm{o}}$ é o preço desse recurso nesses países, em termos de seus custos marginais privados de utilização da água; $\mathrm{g}\left[\mathrm{x}_{\mathrm{o}}, \mathrm{h}\left(\mathrm{x}_{\mathrm{b}}\right)\right]$ é a função de produção agregada dos outros países; $\mathrm{e} h\left(\mathrm{x}_{\mathrm{b}}\right)$ é a restrição que a utilização dos recursos hídricos no Brasil impõe à produção dos outros países, de modo que $h_{\mathrm{f}}=\partial \mathrm{h} / \partial \mathrm{f}\left(\mathrm{x}_{\mathrm{b}}\right)>0$. O nível ótimo de utilização da água nesses países é obtido igualando-se o valor da produtividade marginal da água ao preço desse recurso nesses países, estabelecido pela condição de primeira ordem para um máximo interior ${ }^{3} \mathrm{p}_{\mathrm{o}} \mathrm{g}^{\prime}\left\{\mathrm{x}_{\mathrm{o}}, \mathrm{h}\left[\mathrm{f}\left(\mathrm{x}_{\mathrm{b}}\right)\right]\right\}=\mathrm{w}_{\mathrm{o}}$.

A utilização dos recursos da água na economia brasileira afeta negativamente as atividades produtivas desses países, ao impor limites à capacidade de utilização desses recursos, ademais de incrementar o custo de despoluição nesses países. Fato este que impõe custos sociais, com sérias implicações para toda a comunidade do Mercosul, os quais estão sendo ignorados pelo Brasil nas suas decisões de produção e comercialização e, portanto, não estão sendo contabilizados nos custos dos produtos brasileiros exportados.

Os níveis ótimos de utilização da água para toda a comunidade do Mercosul, sob o ponto de vista social, são aqueles obtidos através de um processo de otimização da função de excedente econômico agregada, p, a qual engloba os excedentes econômicos de todos os países tomados em conjunto, inclusive o Brasil:

\footnotetext{
${ }^{2}$ Supõe-se que a condição de suficiência para um máximo, f">0 é satisfeita.

${ }^{3}$ Supõe-se que a condição de segunda ordem para um máximo interior é também satisfeita, i.e., g">0.
} 


$$
\max \pi=p_{b} f\left(x_{b}\right)+p_{o} g\left\{x_{o}, h\left[f\left(x_{b}\right)\right]\right\}-w_{b} x_{b}-w_{o} x_{o}
$$

Do qual resultam as seguintes condições necessárias para um máximo $\left(\mathrm{p}_{\mathrm{b}}+\mathrm{p}_{\mathrm{o}} \mathrm{g}_{\mathrm{h}} \mathrm{h}_{\mathrm{f}}\right) \mathrm{f}^{\prime}\left(\mathrm{x}_{\mathrm{b}}\right)=\mathrm{w}_{\mathrm{b}}$ e $\mathrm{p}_{\mathrm{o}} \mathrm{g}^{\prime}\left[\mathrm{x}_{\mathrm{o}}, \mathrm{h}\left(\mathrm{x}_{\mathrm{b}}\right)\right]=\mathrm{w}_{\mathrm{o}}$

É importante ressaltar que as condições que estabelecem os níveis ótimos de utilização da água nos outros países, tanto sob a ótica social quanto sob o ponto de vista privado, são exatamente iguais. Isto é, a condição $\mathrm{p}_{\mathrm{o}} \mathrm{g}^{\prime}\left[\mathrm{x}_{\mathrm{o}}, \mathrm{h}\left(\mathrm{x}_{\mathrm{b}}\right)\right]=\mathrm{w}_{\mathrm{o}}$, a qual define o nível de utilização ótimo da água nesses outros países é igual tanto no problema de otimização (2) - sob o ponto de vista privado, quanto no problema (3) - sob a ótica social. No entanto, a condição que estabelece o nível socialmente ótimo de utilização da água na economia brasileira é caracteristicamente diferente daquela obtida pela solução do problema de otimização (1) - sob o ponto de vista privado. Essa diferença, $\mathrm{p}_{\mathrm{o}} \mathrm{g}_{\mathrm{h}} \mathrm{h}_{\mathrm{f}} \mathrm{f}^{\prime}\left(\mathrm{x}_{\mathrm{b}}\right)$, é devido à externalidade tecnológica que $\mathrm{o}$ Brasil impõe aos outros países do Mercosul, ao introduzir restrições técnicas de vazão (menor disponibilidade hídrica), bem como custos adicionais de despoluição, os quais afetam negativamente a economia dos outros países.

A implicação disto é que a economia brasileira não aloca eficientemente os seus recursos da água, de modo que tal recurso é utilizado acima do seu nível socialmente ótimo, $\mathrm{x}_{\mathrm{b}}{ }^{*}$, com impactos negativos para o comércio entre esses países. A FIGURA 1 ilustra esse fato, e mostra que, ao preço $\mathrm{w}_{\mathrm{b}}$, o nível de utilização da água socialmente ótimo $\mathrm{x}_{\mathrm{b}}{ }^{*}<\mathrm{x}_{\mathrm{b}}$. Uma forma de induzir o Brasil a utilizar mais eficientemente os seus recursos hídricos, seria incorporando esse custo social, causado pela maior poluição e menor disponibilidade hídrica, ao preço dos recursos hídricos na economia brasileira, de modo que este preço fosse elevado ao nível $\mathrm{w}_{\mathrm{b}}$ $\mathrm{p}_{\mathrm{o}} \mathrm{g}_{\mathrm{h}} \mathrm{h}_{\mathrm{f}} \mathrm{f}^{\prime}\left(\mathrm{x}_{\mathrm{b}}\right)$ e cujo diferencial de preço seria repassado ao Brasil pelos outros países do Mercosul, através de um sistema de compensação financeira pela melhoria ambiental e maior eficiência no uso desses recursos.

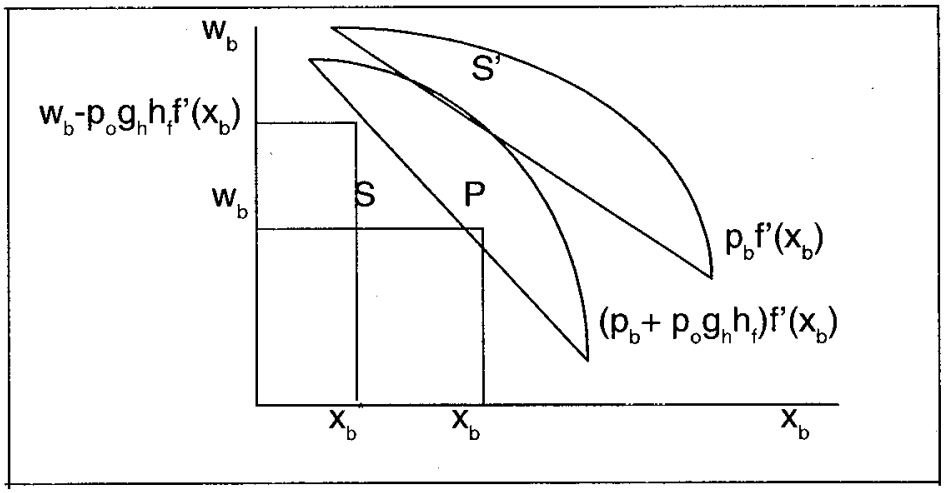

Figura 1: Alocação dos recursos hídricos na economia brasileira 
Nesse sentido, pode-se afirmar que o Brasil, ao utilizar seus recursos hídricos de forma incorreta e, portanto, adotando padrões ambientais menos rigorosos, pode ser visto como dando subsídios implícitos aos produtos exportados (ecodumping), na medida em que estes custos ambientais não são internalizados aos preços de mercado dos produtos exportados. Com base nessa realidade, torna-se indispensável que se faça a correção dos preços de mercado, de modo que a produção brasileira reflita os custos verdadeiramente incorridos pela sociedade do Mercosul.

Em realidade, a razão que leva a produção brasileira a alocar os recursos da água ineficientemente é que inexiste o mercado de água nesses países. Se os direitos de uso da água nesses países estivessem bem definidos e se a legislação que regula a formação do Mercosul contemplasse tanto a cobrança pelo uso dos recursos da água quanto o sistema de compensação ambiental, por certo esta distorção na alocação dos recursos da água seria minimizada ou até mesmo eliminada, com ganhos sociais para toda a comunidade do Mercosul.

\section{Determinação do custo social dos recursos hídricos}

É claro que o máximo valor que a comunidade do Mercosul estaria disposta a pagar para ter uma pequena redução dessas restrições impostas aos outros países a jusante, seria a variação marginal nos lucros dos outros países que a adoção do nível de utilização ótimo dos recursos hídricos no Brasil possibilitaria. Isso pode ser facilmente visto diferenciando-se a função de lucro dos outros países, $\mathrm{p}_{\mathrm{o}}\left\{\mathrm{x}_{\mathrm{o}} \mathrm{h}\left[\mathrm{f}\left(\mathrm{x}_{\mathrm{b}}\right)\right]\right\}$, em relação $\mathrm{h}$, do qual resulta: $\mathrm{dp}_{\mathrm{o}} / \mathrm{dh}=$ $\left(\partial \mathrm{p}_{\mathrm{o}} / \partial \mathrm{x}_{\mathrm{o}}\right)\left(\mathrm{dx}_{\mathrm{o}} / \mathrm{dh}\right)+\left(\partial \mathrm{p}_{\mathrm{o}} / \partial \mathrm{h}\right)$. O teorema da envoltória garante que $\partial \mathrm{p}_{\mathrm{o}} / \partial \mathrm{x}_{\mathrm{o}}=0$, visto que a utilização ótima da água nos outros países é assegurada ao nível que maximiza o lucro dessa atividade. Assim, é necessário avaliar apenas o termo $\partial \mathrm{p}_{\mathrm{o}} / \partial \mathrm{h}=\mathrm{p}_{\mathrm{o}} \mathrm{g}_{\mathrm{h}}$, que é exatamente o custo marginal social de utilizar $1 \mathrm{~m}^{3}$ a mais de água na economia brasileira ${ }^{4}$.

$O$ termo $-\mathrm{p}_{\mathrm{o}} \mathrm{g}_{\mathrm{h}} \mathrm{h}_{\mathrm{f}} \mathrm{f}^{\prime}\left(\mathrm{x}_{\mathrm{b}}\right)$ é, portanto, o custo de oportunidade da água para a sociedade brasileira, proxy para o custo incorrido pela sociedade pela utilização dos recursos hídricos, o qual será denotado por $\mathrm{c}_{\mathrm{b}}$. Este é, em realidade, o custo que o Brasil impõe aos outros países do Mercosul ao utilizarem os recursos hídricos a montante. Este custo pode ser decomposto em duas parcelas multiplicativas: (a) $-\mathrm{p}_{\mathrm{o}} \mathrm{g}_{\mathrm{h}}$, a qual representa o custo marginal social de utilizar $1 \mathrm{~m}^{3}$ a mais de água na economia brasileira e (b) $\mathrm{h}_{\mathrm{f}} \mathrm{f}^{\prime}\left(\mathrm{x}_{\mathrm{b}}\right)$, o requerimento técnico de utilização da água exigido pela economia brasileira.

\footnotetext{
${ }^{4}$ Se esse custo fosse internalizado aos custos privados de produção no Brasil, de modo a estar contido no excedente econômico desse setor, i.e., $\pi_{b}=\mathrm{p}_{\mathrm{b}} \mathrm{f}\left(\mathrm{x}_{\mathrm{b}}\right)+\left(\partial \pi_{\mathrm{o}} / \partial \mathrm{h}\right) \mathrm{h}\left[\mathrm{f}\left(\mathrm{x}_{\mathrm{b}}\right)\right]-\mathrm{w}_{\mathrm{b}} \mathrm{x}_{\mathrm{b}}$, então o resultado seria socialmente eficiente, desde que a maximização do excedente econômico brasileiro gerasse a mesma condição necessária para um ótimo social $\left[\mathrm{p}_{\mathrm{b}}+\left(\partial \pi_{\mathrm{o}} / \partial \mathrm{h}\right) \mathrm{h}_{\mathrm{f}}\right] \mathrm{f}^{\prime}\left(\mathrm{x}_{\mathrm{b}}\right)=\mathrm{w}_{\mathrm{b}}$, visto que $\partial \pi_{\mathrm{o}} / \partial \mathrm{h}=\mathrm{p}_{\mathrm{o}} \mathrm{g}_{\mathrm{b}}$.
} 
O custo de oportunidade da água na economia brasileira deve ser avaliado ao preço de reserva da água ${ }^{5}$ nos outros países a jusante, o qual é definido pelo máximo valor que esses países, em conjunto, estariam dispostos a pagar por cada $\mathrm{m}^{3}$ adicional de água de boa qualidade nas suas economias e permanecerem indiferentes entre continuarem a produzir com os mesmos níveis de utilização e poluição dos recursos hídricos ou produzirem com níveis ótimos de utilização e poluição e, conseqüentemente, com custos mais baixos de despoluição e maior disponibilidade hídrica. Este máximo valor é o lucro adicional que estes países obteriam ao produzirem com custos de despoluição mais baixos e com uma maior disponibilidade hídrica do sistema. Assim, o preço de reserva da água nesses países, $\mathrm{p}_{\mathrm{o}}{ }^{\mathrm{r}}$, pode ser computado da seguinte forma:

$$
p_{o}^{\prime}=\left(C_{M}-C_{m}\right) / x_{o}+w_{o}^{\prime}
$$

Onde: $w_{\mathrm{o}}{ }^{\mathrm{r}}$ é o custo de oportunidade da água para essas economias ${ }^{6}, \mathrm{x}_{\mathrm{o}}$ é o volume de água utilizado pelos outros países do Mercosul por unidade de tempo; $\mathrm{C}_{\mathrm{M}}$ é o custo privado de captação dos recursos hídricos com um maior nível de poluição; e $\mathrm{C}_{\mathrm{m}}$ é o custo privado de captação dos recursos hídricos quando a economia brasileira utiliza esses recursos ao nível socialmente ótimo, i.e., com um nível ótimo de poluição. Deve-se ressaltar que o diferencial de custos $\left(\mathrm{C}_{\mathrm{M}}-\mathrm{C}_{\mathrm{m}}\right)$ na expressão (4) representa a renda ou quase-renda apropriada pelos outros países, ao terem seus custos de despoluição reduzidos.

Vale a pena ressaltar que embora esse custo social seja originado na atividade econômica brasileira, ele se reflete nas economias dos outros países do Mercosul. A não incorporação desse custo à estrutura de preços de mercado pode contrastar com as novas tendências mundiais de comércio, em que a utilização eficiente dos recursos e a questão ambiental são cada vez mais priorizadas.

Acordos bilaterais no sentido de introduzir mecanismos de compensação financeira nas transações comerciais entre esses países, objetivando atingir a eficiência no uso dos recursos hídricos e uma adequação ao meio ambiente, podem evitar atritos econômicos e sociais graves no futuro. Fechar os olhos a essa questão, poderá tornar inviável o próprio acordo comercial entre os países do Mercosul.

${ }^{5} \mathrm{O}$ preço de reserva representa a altura da curva de demanda "tudo ou nada", a qual é definida por:

$$
p_{b}{ }^{r}\left(x_{b}\right)=\left(1 / x_{b}\right) \int_{0}^{x_{b}} p_{b}\left(x_{b}\right) d x_{b}
$$

Da qual a demanda ordinária (Marshalliana ou Walrasiana) é a curva marginal. Isto é, uma é a transformada da outra, por um processo de derivação ou integração.

${ }^{6}$ Admitindo-se que a agricultura irrigada é o uso preponderante nesses países, então o custo de oportunidade, $\mathrm{w}_{0}{ }^{\mathrm{r}}$, poderia ser computado através do custo de oportunidade da água nesse uso, $\mathrm{w}_{\mathrm{i}}^{\mathrm{r}}$, avaliado pelo aumento da produção agrícola através do acréscimo das áreas irrigadas proveniente de uma maior disponibilidade hídrica. 


\section{Conclusões}

Este artigo chama atenção para o fato de que é através do mecanismo de mercado de direitos de uso da água que a otimização dos recursos hídricos pode ser alcançada. A solução mais eficiente de resolver os problemas ambientais associados com a utilização dos recursos hídricos passa pela revisão dos padrões ambientais internacionais, através da imposição de preços de mercado mais realistas aos recursos hídricos. Para isso, é necessário que a legislação que regula Mercosul, contemple não apenas um sistema bem definido de direitos de uso da água, os quais possam ser transferidos entre os múltiplos usuários do sistema, mas principalmente permita criar um sistema de compensações financeiras, como forma de melhorar a eficiência no uso desses recursos e induzir uma maior conscientização ecológica.

Embora a cobrança pela utilização dos recursos hídricos e, principalmente, a compensação financeira sejam mecanismos relativamente novos, eles são amplamente reconhecidos na literatura e mais recentemente nos foros internacionais. Cabe aos países do Mercosul e especialmente o Brasil, como líder que é desse bloco de livre comércio, lutar para que esses mecanismos sejam viabilizados e implementados. A não antecipação dessas tendências ambientais poderá acarretar perdas de competitividade desses países no mercado internacional, na medida em que se estará criando uma estrutura industrial dissociada dos padrões de eficiência econômica internacionais, ecologicamente apropriados.

\section{Referências bibliográficas}

BAUMOL, W, OATES, W. The theory of environmental policy. Cambridge: University Press, 1988.

CARRERA-FERNANDEZ, José Otimização de usos múltiplos na bacia do Alto Paraguaçu. Salvador: SRH/BA, 1993. (relatório de consultoria).

Cobrança e preços ótimos pelo uso e poluição da água de mananciais. Revista Econômica do Nordeste, Fortaleza; v. 28, n. 3, 1997a.

Usos da água: aspectos econômicos: notas de aula para o curso de pósgraduação (lato senso) de gerenciamento e conservação de recursos hídricos. Salvador: Centro Interamericano de Recursos da Água - CIRA/UCSal, 1997b.

O custo social da energia elétrica no Brasil. Salvador: Relatório de pesquisa/ CME-UFBA, $1997 \mathrm{c}$.

COMISIÓN ECONOMICA PARA AMÉRICA L.ATINA y el CARIBE (CEPAL). Agua, desarrollo y medio ambiente en America Latina. Santiago del Chile: CEPAL, 1980. .Inventario de los recursos hídricos y su utilización. Santiago del Chile: CEPAL, v. II, 1990.

.Los recursos hidricos de America Latina y el Caribe: planificación, desastres naturales y contaminación. Santiago del Chile: CEPAL, 1990a. 
COMISIÓN ECONOMICA PARA AMÉRICA LATINA y el CARIBE (CEPAL).Guia sobre la administración de los recursos hídricos en los paises de America latina e el Caribe. Santiago del Chile: CEPAL, 1995.

COASE, Ronald. The problem of social cost. Jornal of Law and Economics, 1960.

EWERS, Hans-Jürgen. O programa de um imposto ecológico e os seus efeitos sobre o sistema tributário alemão. CARRERA-FERNANDEZ, José, GMÜNDER, Ulrich (Orgs.). Uso eficiente de recursos naturais e uma política tributária ecológica. Salvador: Goethe-Institut, 1998.

GUTIERREZ, Maria Bernadete Sarmiento. Comércio e meio ambiente no Mercosul: algumas considerações preliminares. Rio de Janeiro: IPEA, Texto para Discussão, n. $470,1997$.

LIMA, Jandir Ferrera. A geoeconomia da Macrorregião Platense. Dissertação de Mestrado. Salvador: CME/UFBA, 1997.

MILLAR, A. (org.). O gerenciamento dos recursos hídricos e o mercado de águas. Brasília: MIR/SEPLAN/BIRD/IICA), 1994.

MOTTA, Ronaldo Seroa da. Indicadores ambientais no Brasil: aspectos ecológicos, de eficiência e distributivos. Rio de Janeiro: IPEA, Texto para Discussão, n. 403, 1996.

.Desafios ambientais da Economia Brasileira. Rio de Janeiro: IPEA, Texto para Discussão, n. 509, 1997.

PERRONE, Francisco. Infra-estrutura, o motor de novas riquezas e bem-estar. Rumos do Desenvolvimento, n. 140, p.04-09, 1997.

RICHARDSON, Harry. Economia regional. Rio de Janeiro: Zahar, 1973.

SCHILLING, Paulo. O expansionismo brasileiro. São Paulo: Global, 1981. 